\title{
Nocturnal nasogastric tube feeding at home
}

\author{
P. B. MCINTYRE \\ M.B., Ch.B., M.R.C.P. \\ J. POWELL-TUCK* \\ M.D., M.R.C.P.
}

S. R. WOOD

S.R.N., Dip.N.

J. E. LENNARD-JONES
M.D., F.R.C.P.

St Mark's Hospital, City Road, London ECIV 2PS

\begin{abstract}
Summary
Five malnourished patients who consistently failed to maintain or gain weight with other oral diets have been taught to give themselves a nocturnal nasogastric tube feed at home to supplement their dietary intake by day. All patients gained weight at a rate of about $0.5 \mathrm{~kg}$ per week. Nasogastric tube feeding at home can be an acceptable, safe, economical and efficient treatment for nutritional depletion, particularly in patients with a short functional length of small intestine for whom simpler dietary manipulation has been unsuccessful.
\end{abstract}

KEY WORDS: enteral feeding, short bowel syndrome.

\section{Introduction}

Evidence of malnutrition is common in patients with small bowel disease or resection. Severe weight loss leads to weakness, apathy, sensitivity to cold and reduced capacity for physical activity. The malnutrition is usually due to inadequate food intake because of poor appetite or aggravation of symptoms such as pain or diarrhoea. Sometimes malabsorption of food, and possibly protein loss from the gut, are also important factors.

Many malnourished patients are able to increase their calorie intake by adding a liquid supplement to their normal diet. In some, however, this measure is unsuccessful and weight loss continues. It is in such patients that we have used a nocturnal nasogastric tube feed, begun in hospital and continued at home with success. The technique promotes absorption and decreases obstructive symptoms because the feed is given slowly, utilizes the whole $24 \mathrm{hr}$ for feeding and is independent of appetite.

*Present address: Charing Cross Hospital, Fulham Palace Road, London W6 8RE.

\section{Methods}

Patients are taught to pass a soft, fine-bore siliconerubber nasogastric tube (Vygon 2395.06) on themselves at bedtime by a Nursing Sister specialising in nutritional support. This tube has no stilette so there is no risk of the patient traumatizing the oropharynx or oesophagus. However, the tube has to be passed slowly with frequent sips of water because it is pliable and cannot be advanced by pushing. When the tube has been advanced to a mark $60 \mathrm{~cm}$ from its tip, juice is aspirated with a small syringe and tested with litmus paper for acid. The position of the tube is regarded as satisfactory only when acid has been obtained and the tube is then taped to the nose and cheek. The feed is placed in a reusable Viomedex enteral feeding bag with integral giving set (Viomedex VX516) and the rate of infusion regulated using a simple peristaltic pump (Viomedex enteral nutrition pump). Patients are advised to sleep using three pillows in a semi-recumbent position and are encouraged to be flexible about the exact time over which the feed is given.

The feeding bag and nasogastric tube can usually be reused on several occasions with appropriate cleaning.

Three commercially available feeds have been used. Isocal or Ensure, with similar protein, carbohydrate and fat content, and with whole protein as a nitrogen source, have been used for four patients. Nutranel, a low fat preparation containing small peptides as its nitrogen source, was used for one patient with significant steatorrhoea.

\section{Case reports}

Case 1 (D.M.)

This 48-year-old man with Crohn's disease had required repeated resections of small bowel. After proctocolectomy and a further small bowel resection, 
$160 \mathrm{~cm}$ of jejunum remained. Over the next year, his weight dropped from $68.0 \mathrm{~kg}$ to $59.4 \mathrm{~kg}$ (ideal $77 \mathrm{~kg}$ ). Attempts to reduce his 2-litre stoma output with antidiarrhoeal drugs, cimetidine, fat restriction and lactose withdrawal were unsuccessful. Supplementation of his diet with medium chain triglycerides halted weight loss but he could not tolerate the preparation over a prolonged period. Bomb calorimetry of the stoma effluent while on a known calorie input of $3,500 \mathrm{kcal} /$ day revealed the loss of 1800 $\mathrm{kcal} /$ day in the effluent. Nocturnal nasogastric feeding with four cans of Isocal ( 1,500 calories) on each of five nights per week produced a satisfactory gain in weight and maintenance near his ideal weight over 13 months. Rapid weight loss recurred when the feeds were stopped, but was reversed when they were restarted. It subsequently proved possible for him to maintain his weight by taking five cans of Ensure ( 1,250 calories) by mouth each day in addition to his normal diet.

\section{Case 2 (D.M-S.)}

At the age of 22 years, this patient underwent proctocolectomy and subsequently multiple resections of small bowel for enterocutaneous fistulae so that she was left with $80 \mathrm{~cm}$ of jejunum. Despite a full diet of 3,500 calories daily she lost $9 \mathrm{~kg}$ in weight in 5 months after stopping parenteral nutrition. Bomb calorimetry studies revealed that she absorbed only $25 \%$ of calories from a normal diet. She was unable to take a sufficient volume of liquid supplement by day to increase her weight and nocturnal nasogastric feeding was introduced when she weighed $39 \mathrm{~kg}$ (ideal $58 \mathrm{~kg}$ ) with four cans of Ensure (1,000 kcals) in addition to four cans orally by day. Over the next 3 months she gained $6.8 \mathrm{~kg}$. The frequency of her nocturnal supplement was decreased to five nights weekly but she continued to gain weight.

\section{Case 3 (C.W.)}

Since the age of 8 years, this boy had been treated for Crohn's disease involving practically the whole gastrointestinal tract. At the age of 15 years he was known to have duodenal, extensive ileal, colonic and anal Crohn's disease. His height and weight were below the 3rd centile and his bone age was 11.5 years. He was grossly oedematous and the serum albumin was $15 \mathrm{~g} /$ litre. Treatment with oral dietary supplements was unsuccessful because of anorexia. Nasogastric feeding was started using eight cans of Isocal over $24 \mathrm{hr}$ (3,000 kcal), decreasing to four cans each night, in addition to zinc, iron and folic acid supplements. There was rapid resolution of his oedema and over the next 6 months he exhibited catch-up growth and weight gain of $11.9 \mathrm{~kg}$; the serum albumin rose to $35 \mathrm{~g} /$ litre. Treatment con- tinued for 8 months until proctocolectomy was undertaken.

Case 4 (W.D.)

This 49-year-old man underwent three resections for ileal Crohn's disease and was admitted wh recurrent diarrhoea and weight loss one year after the last resection. Radiological investigation revealecha $30 \mathrm{~cm}$ segment of recurrent disease in the remainifg $130 \mathrm{~cm}$ of small bowel. Oral supplements with Nutranel were initially satisfactory and raised firs weight from $48.8 \mathrm{~kg}$ to $51.3 \mathrm{~kg}$ (ideal $66 \mathrm{~kg}$ ). Problemts with palatability led to the patient drinking th preparation rapidly in large boluses causing seve diarrhoea. Nocturnal slow nasogastric feeding, usin̈g five cans of Nutranel each night (2,000 calories) wis commenced and with this supplement he gained 83 $\mathrm{kg}$ in weight over 4 months and has maintained serum albumin depite known protein-losing entergpathy.

\section{Case 5 (M.W.)}

This woman, aged 49 years, presented with f quent loose bowel actions, anorexia and weight loss after colectomy and caeco-rectal anastomosis for ulcerative colitis 9 years previously. Investigåtion revealed no small bowel disease, normal laetose tolerance and faecal fat excretion, but a sệum albumin of $35 \mathrm{~g} /$ litre. Her weight was $39.5 \mathrm{~kg}$ (त्वाद्gl $57.5 \mathrm{~kg}$ ). Anorexia and abdominal pain prevented satisfactory oral supplementation of her diet. Nas gastric feeding was commenced in preparation for rectal excision. Isocal, initially five cans in 24 \$r (1,875 calories), and decreasing eventually to two cans each night, resulted in a weight gain of $5.4 \mathrm{gg}$ over 3 months. She made a trouble-free recovery after operation following which it was not necessapy to continue any dietary supplements.

\section{Discussion}

At the start of treatment, all these patients we significantly below their ideal weight, mean $29.3 \%$ (range 15.5-46.3\%). The figure illustrates the satisfactory weight gain as a result of the self-administereg tube feed. The mean rate of weight gain in the first $\$$ weeks of treatment was $0.54 \mathrm{~kg}$ per week (ran $0.42-0.61 \mathrm{~kg}$ per week). One patient had significaAt hypoalbuminaemia of $15 \mathrm{~g} /$ /itre which increased tog normal level of $35 \mathrm{~g} /$ litre.

No patient suffered regurgitation or aspiration $\underset{\Theta f}{\omega}$ the nasogastric feed and there were no metabolic complications. Diarrhoea, abdominal pain and bloafing in one patient were dealt with by decreasing the amount of feed given. Two patients with stomas 


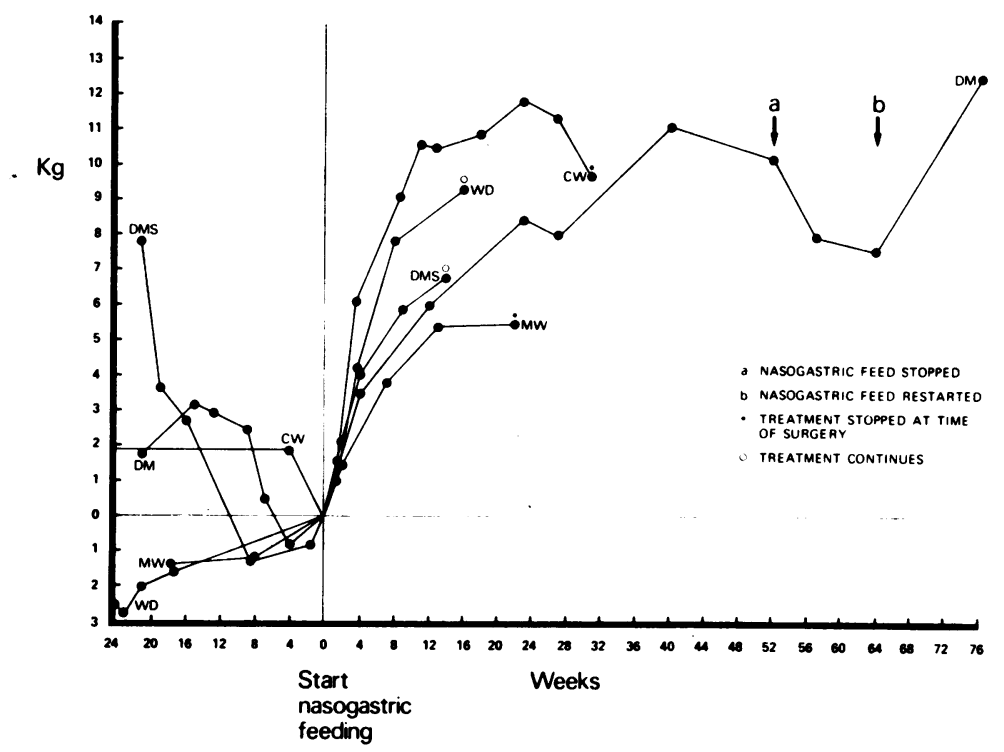

FIG. 1. Weight gain following the introduction of nocturnal nasogastric feeding in five patients.

reported an increase in nocturnal effluent, but did not have to empty the bag more frequently.

Although Jones, Payne and Silk (1980) have shown that feeds can be given satisfactorily by gravity in boepital, the use of an infusion pump is recommended at home because the patient can sleep uninterruptedly without worry that the drip will stop or that the rate of infusion will change. Using this technique $\mathrm{i}$ has been possible to administer a supplement of 1,000-2,000 kcal each night without difficulty. This supplement to the normal daily intake has permitted weight gain. In two of these patients, balnace studies have shown deficient absorption of calories so that the patient has needed a greater than normal intake to gain weight and even to maintain it. In other patients, a nocturnal tube feed has permitted weight gain but once ideal weight has been restored it has been possible to maintain weight with oral supplements by day. A slow infusion of isotonic nutrient permits maximum utilization of residual small bowel function.

Our experience, and that of Main et al. (1980), and Greene et al. (1981) suggests that nasogastric tube feeding at home can be an acceptable, safe, economical and efficient treatment for nutritional depletion, particularly for patients with a short functional length of small intestine when simpler dietary manipulation has been successful. This technique can sometimes be used in place of the potentially more hazardous and expensive technique of home parenteral nutrition.

\section{References}

Greene, H.L., Helinek, G.L., Folk, C.C., Courtney, M. Thompson, S., MacDonnell, R.C. \& Lukens, J.N. (1981) Nasogastric tube feeding at home: a method for adjunctive nutritional support of malnourished patients. American Journal of Clinical Nutrition, 34, 1131.

Jones, B.J.M., PAYNe, S. \& Silk, D.B.A. (1980) Indications for pump-assisted enteral feeding. Lancet, i, 1057.

Main, A.N., Morgan, R.J., Hall, M.J., Russell, R.I., Shenkin, A. \& FELL, G.S. (1980) Home enteral tube feeding with a liquid diet in the longterm management of inflammatory bowel disease. Scottish Medical Journal, 25, 312.

(Accepted 26 April 1983) 